\title{
PENINGKATAN KAPASITAS PRODUKSI PENGRAJIN KERIPIK SINGKONG DENGAN MENGGUNAKAN MESIN PERAJANG ROTARI
}

\author{
Darmanto $^{1}$, Tabah Priangkoso ${ }^{2}$ \\ ${ }^{1}$ Jurusan Teknik Mesin, Fakultas Teknik, Universitas Wahid Hasyim \\ Jl. Menoreh Tengah X/22, Sampangan, Semarang 50236. \\ ${ }^{2}$ Jurusan Teknik Mesin, Fakultas Teknik, Universitas Wahid Hasyim \\ Jl. Menoreh Tengah X/22, Sampangan, Semarang 50236 \\ "Email: darmanto@unwahas.ac.id
}

\begin{abstract}
Abstrak
Keripik Singkong merupakan makanan kecil yang terbuat dari ketela pohon yang diiris tipis-tipis lalu digoreng dengan minyak. Kendala yang dihadapi oleh pengrajin di Desa Bringin, Kec Godong, Kab. Groboganini adalah alat perajang yang masih sangat tradisional, sehingga masing memerlukan tenaga manusia yang besar dan kapasitas yang dihasilkan masih sangat sedikit. Program yang diusulkan untuk dilaksanakan adalah pembuatan alat perajang keripik singkong rotari dengan 4 mata pisau dengan penggerak motor listrik. Dengan alat ini diharapkan proses produksi menjadi lebih efisien dengan kapasitas lebih besar. Seluruh kegiatan melibatkan mitra dan di akhir program akan dilakukan evaluasi secara keseluruhan
\end{abstract}

Kata kunci : Keripik singkong, perajang rotari, efisien

\section{PENDAHULUAN}

Desa Bringin, Kecamatan Godong Kabupaten Grobogan memiliki potensi besar di bidang pertanian. Tanaman yang dikembangkan adalah padi untuk persawahan, sedangkan ladang ditanami palawija seperti jagung, kedelai, kacang dan singkong. Khusus untuk Kecamatan Godong, total produksi singkong yang dihasilkan 925 ton. (Anonimous, 2015)

Singkong (Manihot utilissima Crantz) meruPakan tanaman yang tidak mengenal musim. Tanaman ini dimanfaatkan umbinya untuk sumber karbohidrat dan serat, sedangkan daunnya untuk sayuran. Tanaman ini cukup disukai warga karena cara menanam dan perawatanya sangat mudah, dan ketela pohon ini dapat ditanam di sekitar rumah. Umur tanaman singkong dari tanam sampai panen 9 12 bulan.

Di salah satu desa di Kecamatan Godong, yaitu Desa Bringin, terdapat Kelompok Usaha Bersama (KUB) keripik singkong yang memanfaatkan hasil pertanian setempat, diantara anggotanya adalah Pak Hadi Prayitno sebagai mitra untuk dipecahkan masalahnya dalam kegiatan pengabdian kepada masyarakat. Pak Hadi Prayitno dan istri sudah menekuni usaha ini selama 5 tahun dan sudah mengantongi ijin PIRT dari Dinas Kesehatan Kabupaten Grobogan.

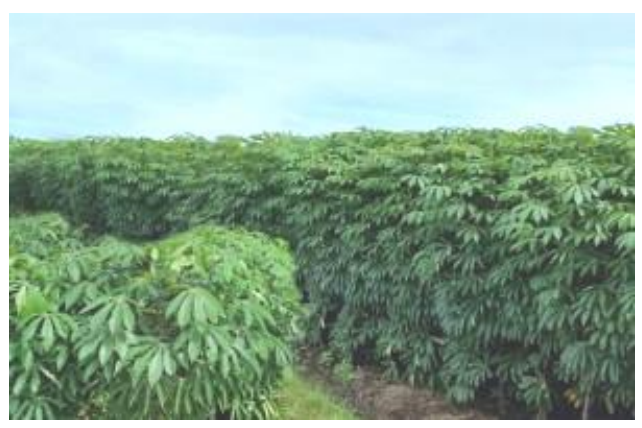

Gambar 1 Tanaman Singkong

Kapasitas produksi usaha Pak Hadi Prayitno masih sangat sedikit yaitu 10 - $20 \mathrm{~kg}$ setiap hari dan hanya dikerjakan sendiri. Pada saat menjelang lebaran kapasitas produksi bisa sampai $100 \mathrm{~kg} / \mathrm{hari}$ dengan menambah tenaga kerja. 
Keripik singkong adalah salah satu olahan umbi singkong sebagai makanan ringan. Cara membuatnya cukup sederhana. Umbi singkong diiris tipis, digoreng, kemudian diberi bumbu tertentu atau hanya garam. Setelah itu langsung dikemas. (Koswara)

Pak Hadi Prayitno melakukan pembuatan keripik singkong dengan urutan keripik singkong dikupas terlebih dahulu lalu dirajang tipis-tipis dan langsung dimasukan penggorengan yang telah berisi minyak panas. Setelah kurang lebih 10 menit singkong diangkat dan ditiriskan.

Kendala utama yang dihadapi Pak Hadi Prayitno dan kawan-kawan adalah dalam mengiris tipis singkong masih menggunakan perajang tradisional/manual. Perajang manual memerlukan tenaga yang cukup besar dan sangat tidak efisien. Alat perajang tradisional ini terbuat dari papan kayu dan dipasang pisau pada bagian tengahnya. Selain tidak efisien, alat ini juga berbahaya karena jika tidak hati-hati menggunakannya, pisaunya dapat melukai jari tangan.

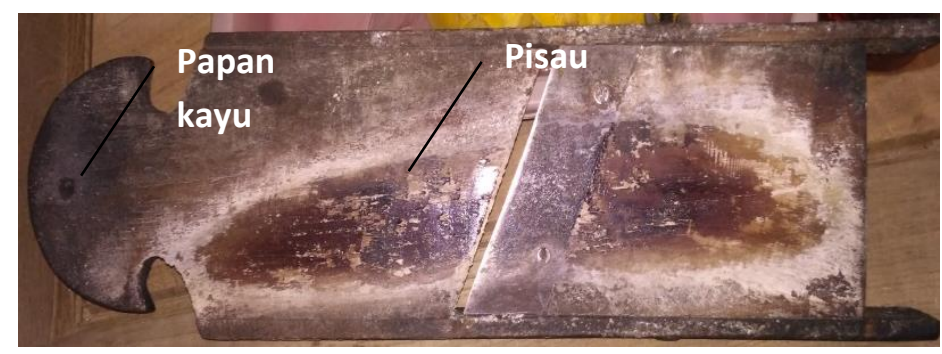

Gambar 2 Alat perajang keripik singkong tradisional

Pemecahan masalah yang diusulkan adalah mekanisasi perajang keripik singkong sebagai pengganti alat perajang tradisional. Selain meningkatkan keselamatan, penggunaan mesin perajang singkong juga meningkatkan efisiensi dan produktivitas usaha keripik singkong.

\section{METODE}

Masalah mitra diselesaikan melalui pembuatan Mesin Perajang Singkong sistem rotari dengan menggunakan 4 (empat) pisau. Pembuatan mesin perajang singkong diawali dengan perancangan desain di Laboratorium Perancangan Jurusan Teknik Mesin Unwahas dan proses pembuatannya dilakukan di Laboratorium Proses Produksi Jurusan Teknik Mesin Unwahas. Hasil rancangan ditunjukkan pada Gambar 3, sedangkan mesin perajang singkong ditunjukkan pada Gambar 4.
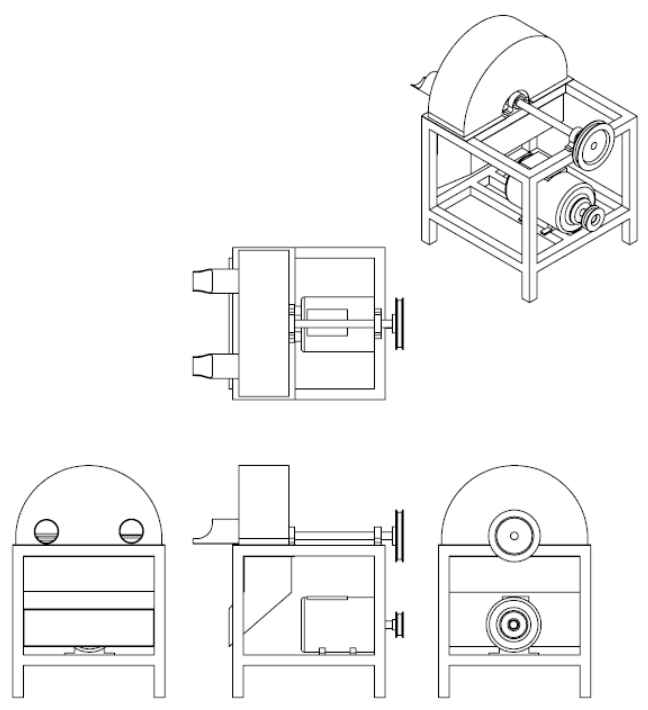

Gambar 3 Desain Mesin perajang singkong sistem rotari 
Spesifikasi alat perajang singkong rotari adalah sebagai berikut:
Kapasitas
: $25 \mathrm{~kg} / \mathrm{jam}$
Dimensi
: $50 \times 50 \times 50 \mathrm{~cm}$
Material
: Besi, aluminium dan stainlesteel
Pisau
$: 4 \mathrm{pc}$
Jenis perajang : Rotari

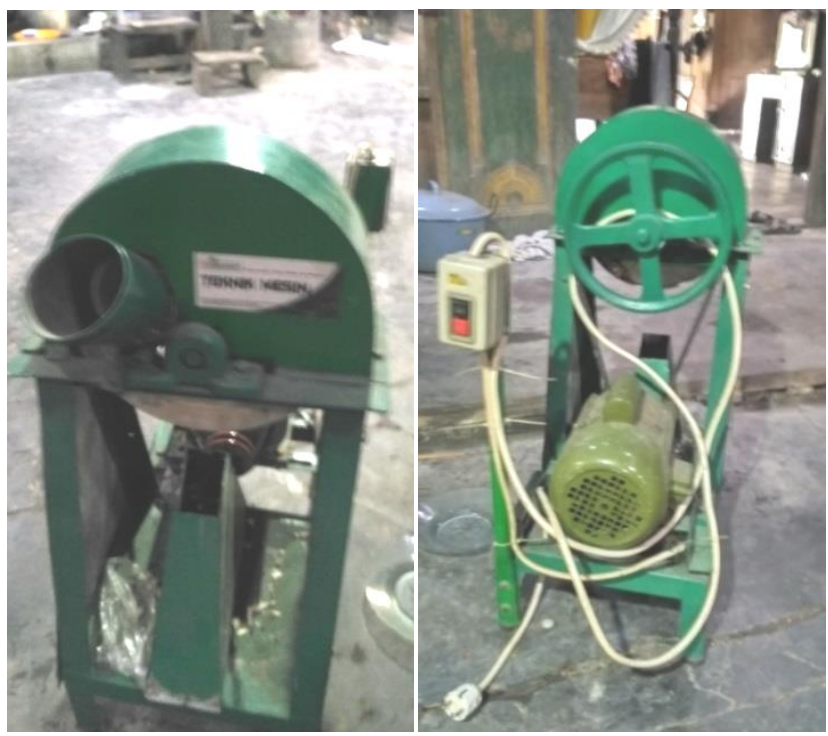

Gambar 4 Alat perajang singkong sistem Rotari

\section{HASIL DAN PEMBAHASAN}

Mesin perajang singkong telah diserahkan kepada Pak Hadi Prayitno untuk digunakan dalam produksi keripik singkong. Penggunaan mesin perajang singkong mempersingkat waktu perajangan sehingga secara langsung juga mempersingkat waktu produksi. Mengingat kapasitas produksi mesin masih tersisa jika digunakan sendiri oleh Pak Hadi Prayitno, maka mesin perajang singkong tersebut juga digunakan bersama anggota Kelompok Usaha Bersama (KUB) keripik singkong di Desa Beringin.

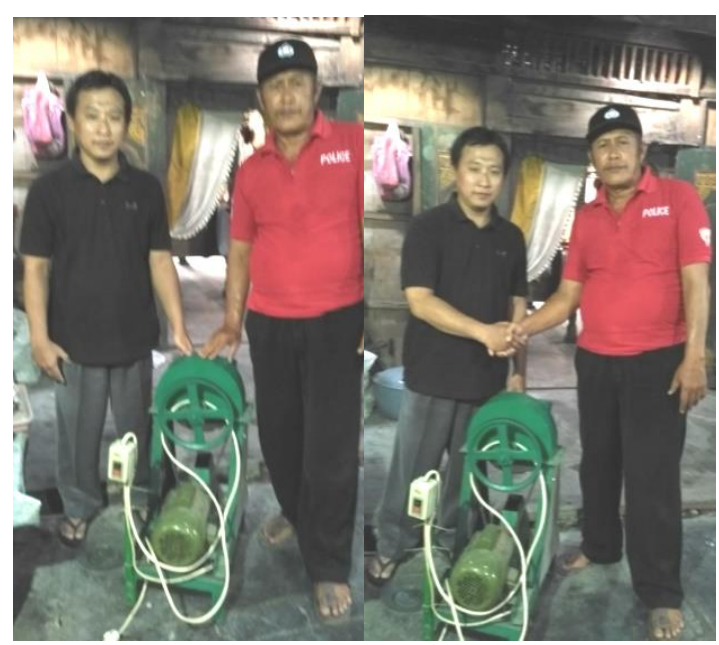

Gambar 5 Penyerahan mesin perajang singkong rotari 


\section{KESIMPULAN}

Alat perajang singkong dengan sistem rotari dapat meningkatkan kapasitas produksi pengrajin dan jauh lebih efiesien dibandingkan dengan cara manual. Dan Diperlukan pendampingan terus menerus dari pihak terkait di pemkab Grobogan agar kualitas dan kuantitas produksi tetap terjaga.

\section{DAFTAR PUSTAKA}

Anonimous, 2015, Luas Panen Dan Produksi Tanaman Jagung, Ketela Pohon, Dan Ketela Rambat Menurut Kecamatan 2013, Dipetik 10 Mei 2017, dari Badan Pusat Statistik Kabupaten Grobogan:Https://grobogankab.bps.go.id/statictable/2014/12/30/67/luas-panen-dan produksitanaman-jagung-ketela-dan-ketela-rambat-menurut-kecamatan-2013-html

Koswara, S, Pengolahan Singkong dalam Tehnologi Pengolahan umbi-umbian, Bogor: Southeast Asian Food And Agricultural Science And Tehnology IPB 